\title{
Study on the Technical Efficiency of Creative Human Capital in China by Three-Stage Data Envelopment Analysis Model
}

\author{
Jian Ma, ${ }^{1}$ Yueru Ma, ${ }^{1}$ Yong Bai, ${ }^{1,2}$ and Bing Xia ${ }^{1}$ \\ ${ }^{1}$ Business School, Central South University, Changsha Hunan 410083, China \\ ${ }^{2}$ Business School, Hunan International Economics University, Changsha Hunan 410205, China \\ Correspondence should be addressed to Yong Bai; baiyong1225@163.com
}

Received 24 December 2013; Accepted 26 January 2014; Published 11 March 2014

Academic Editor: Taishan Yi

Copyright (c) 2014 Jian Ma et al. This is an open access article distributed under the Creative Commons Attribution License, which permits unrestricted use, distribution, and reproduction in any medium, provided the original work is properly cited.

\begin{abstract}
Previous researches have proved the positive effect of creative human capital and its development on the development of economy. Yet, the technical efficiency of creative human capital and its effects are still under research. The authors are trying to estimate the technical efficiency value in Chinese context, which is adjusted by the environmental variables and statistical noises, by establishing a three-stage data envelopment analysis model, using data from 2003 to 2010 . The research results indicate that, in this period, the entirety of creative human capital in China and the technical efficiency value in different regions and different provinces is still in the low level and could be promoted. Otherwise, technical non-efficiency is mostly derived from the scale nonefficiency and rarely affected by pure technical efficiency. The research also examines environmental variables' marked effects on the technical efficiency, and it shows that different environmental variables differ in the aspect of their own effects. The expansion of the scale of education, development of healthy environment, growth of GDP, development of skill training, and population migration could reduce the input of creative human capital and promote the technical efficiency, while development of trade and institutional change, on the contrary, would block the input of creative human capital and the promotion the technical efficiency.
\end{abstract}

\section{Introduction}

Since American economist Schultz put forward Human Capital Theory in 1960s, the Human Capital Theory and its impact on social and economic development are one of the hot research issues for specialists and scholars at home and aboard. It is generally accepted that human capital is a reflection of the quality of labor capital, and human capital consists of economic value of knowledge, technology, ability, and healthy quality which condenses on laborers $[1,2]$. Human capital usually has greater appreciation of space than material capital and other production factors, especially in the postindustry era and in the stage of rapid economic knowledge development. As a "live" capital form, human capital, with its creativity and innovation, has greater value and development potential in the aspects of optimizing allocation of resources or speeding up the economic development and promoting the social progress. Human capital, as one of those main production factors which can facilitate the economic growth, has an immediate boost to economic growth and would generate technology spillover effect by material capital and foreign direct investment (FDI) [3], spiritual morality [4], and other factors; thus it indirectly promotes economic growth. A lot of researches show that human capital is playing a more and more significant role in the development of national culture or society or economy or employment or income and so on [5-8].

Schultz claimed that the contribution to economic growth from the improvement of human capital such as human's knowledge or ability and health is more important than the increase of material force and the number of labor [9]. Generally, the formation of human capital mainly depends on the input of education, health and income, and so forth $[10,11]$. The differences among education investment, health investment, and family economic income invariably tend to raise up the differences of human capital stock directly $[12,13]$, while the differences of human capital will lead to the differences of their effects. Studies have shown that the effects of human capital that received higher education, on individual performance, total productivity, technological progress, economic growth, and international trade, are 
significantly greater than the human capital which received secondary education and basic education [14-18]. According to the differences of human capital stock, human capital can be divided into general human capital, professional human capital, and creative human capital. The general human capital contains social average knowledge stock and the ability of analysis, computing ability, learning ability, and adaptability, and the corresponding social role is the division of ordinary workers. Professional human capital has a special professional knowledge and professional ability, which generally accepts special professional knowledge through formal education or on-the-job training. Creative human capital is a kind of innovative knowledge and a scarcity of innovative ability, which can realize increasing return of heterogeneity of human capital [19], and it is usually characterized by receiving higher education and is scarce in society, which means high reserve, specialization, and innovation [20]. Creative human capital would develop the ability to discover and resolve the market disequilibrium $[9,21]$ and then bring about more creation in strategy, institution, method, science, and technology more easily. These innovative activities tend to break through the bottlenecks in the system of technology or production constraints, make the enterprise production possibilities frontier outward or the moving-up of production function, and bring the output multiplier effect. On the one hand, creative human capital can produce its own progressive increase of marginal revenue through specialization of knowledge factors. On the other hand, through the overflow effect of knowledge, it can promote the production efficiency of the production factors like capital and labor and produce progressive increase of marginal revenue of these factors and eventually progressive increase of production scale revenue [22]. Therefore, the influence of creative human capital on the economic growth is greater than other types of human capital $[23,24]$.

For most developing countries, including China, the development of knowledge economy and the increase of human capital could effectively promote the economic growth rapidly [5]. In recent years, the economy in China has made rapid development, but the contribution of economic growth still mainly relies on capital investment [25]. Therefore, in order to ensure the long-term stable development of Chinese economy, it is important to increase the investment of human capital, especially the creative human capital, and to improve the efficiency of the quality of the creative human capital and technology. Continuously strengthening the role of creative human capital on economic growth is particularly important.

According to the studies of human capital, if only it limits to the single factor index of human capital investment and ignores many other factors, which tends to ignore the heterogeneity of human capital under different investment structure, so that human capital stock index is short of enough accuracy on the basis of building [26]. Therefore, the study of human capital should not only consider the number, but also need to pay attention to structure. The number and structure of the human capital investment directly restrict the amounts and the formation of human capital and thus affect the economic operation performance [27]. The investment and accumulation of human capital do not only depend on the micro main body of education or health or migration, but also depend on whether the macroeconomic system is conductive to development of the micro main body by using the potential of its investment and making it the reality of human capital or not [28]. The technical efficiency of human capital and its effect on economic growth would differ for each investment structure of human capital and each environment. Therefore, the creative human capital stock and the technical efficiency of the investment structure should both be considered when analyzing the influence of creative human capital.

Currently, some scholars studied the efficiency of human capital, such as Ferrari and Laureti who have carried an empirical research, using DEA method, on output efficiency of human capital in Italian university, based on data from the students of Florence University in 2005 [29]; Chang et al. have made an empirical analysis on the efficiency of intellectual capital and its effect on the performance in the digital industry in Taiwan by using the DEA method [30]. Ahmed and Krishnasamy have analyzed the efficiency of human capital investment and its effect on the increase of total factor productivity (TFP) in ASEAN countries [31]. Maudos et al. in 2006 [32] and Zhu et al. in 2010 [33] used SFA method to analyze the effect of human capital and its components on technical change, technical efficiency, and productivity; Ran and Zhai used DEA method to make an empirical analysis of the construction industry contribution rate of human capital in China [34]. However, few researches on the efficiency of creative human capital have been done at present.

Compared to traditional view of frontier efficiency analysis methods, such as DEA method, Fried et al. put forward the three-stage DEA method to effectively strip the influence of environment factors and the random errors on the efficiency value, overcoming the traditional shortcomings in frontier efficiency analysis model in measuring error handling [35]. This paper attempts to construct the forefront of creative human capital efficiency analysis model by using three-stage DEA method as the theoretical model, based on panel data of 31 provinces in China from 2003 to 2010. Then a quantitative research on the efficiency of creative human capital in China and the influence of its environmental factors and random errors would be made in order to support effective decisionmaking in promoting the development of creative human capital and improving the technology efficiency of creative human capital in China.

\section{Establishing the Theoretical Model}

Based on the Data Envelopment Analysis (DEA) model founded by Charnes et al. in 1978 and two-phase DEA model by Coelli in 1998, three-stage DEA model proposed by Fried et al. has been proved to be a better method to assess the efficiency of Decision-Making Units (DMU) [35]. Its contracture and application include three stages.

2.1. The First Stage: Traditional DEA Model. Charnes et al. put forward a DEA method which was called efficiency measurement model and was based on the Constant Return Scale (CRS) in 1978 [36]. According to the multiple sets of input and output data of the technical efficiency of DMU, the CCR 
model assumption with fixed size is not consistent with the practical situation of many industries by using the theory of mathematical programming. In 1984, Banker et al. changed the assumption of Constant Return Scale into Variable Return Scale (VRS) and built a more rigorous variable scale reward model to decompose the technical efficiency (TE) into pure technical efficiency (PTE) and scale efficiency (SE), TE $=$ PTE $\times$ SE [37].

Generally speaking, the technical efficiency of DMU can be estimated by two ways. One is based on input technical efficiency, namely, the proportion of the minimum investment in the investment under a certain output. Another is based on the production technical efficiency, namely, the proportion of the maximum output in the practical output under the certain investment combination. The BBC model of variable returns to scale adopts the efficiency estimation when input is at the minimum level under the condition of constant output. In this paper, technical efficiency is defined as the proportion between minimum possible input and practical investment in the same deal, $0 \leq \mathrm{TE} \leq 1$. The bigger the value of $\mathrm{TE}$ is, the higher the efficiency level of DMU's production is. If TE $=1$, the DMU has reached the minimum input under the certain constant output and realized the optimal allocation of resources. If $\mathrm{TE}<1$, it means that the DMU has not yet achieved the optimal allocation of productive resources while production technology is inefficient.

BCC model argues that the reasons of technical inefficiency are two: low efficiency of production technology and nonefficiency which is not at the optimal size. Pure technical efficiency of DMU refers to the production efficiency that is affected by management and technology factors, and it can reflect the production efficiency of input factors when production scale has reached the optimal level, namely, $0 \leq$ $\mathrm{PTE} \leq 1$. If the $\mathrm{PTE}=1$, it means that under the current technical level, the utilization of DMU input resources is efficient, or there is lack of efficiency. Scale efficiency of DMU refers to the production efficiency that is affected by scale factor, which reflects the difference between the practical production scale and the optimal production scale. If $\mathrm{SE}=$ $1, \mathrm{DMU}$ is in the state of optimal production scale, or it has not yet reached the optimal production scale.

The analysis result of $\mathrm{BBC}$ model can measure the utilization efficiency of production factors when the output is constant of each DMU. The decomposition results of the production inefficiency can accurately reflect the reason of inefficiency of production input of the DMU and thereby could support the improvement of the utilization efficiency in the production process and provide the solution and method to achieve the optimal distribution of input factors.

This article adopts the BCC model of the Variable Return Scale (VRS) and regards creative human capital investment as an independent production process, in order to measure the minimum level of investment of creative human capital to achieve a certain level. The technical efficiency (TE) of the scale-reward of creative human capital can be divided into pure technical efficiency (PTE) and scale efficiency (SE), leading to the separation of the two different causes that are the inefficiency of production technology and the inefficiency of the investment size which is less than optimal of the inefficiency of creative human capital.

Then, review the management efficiency of creative human capital in $k$ city $\left(\mathrm{PTE}_{k}\right)$ in China; each province has $m$ inputs and $s$ output, and the investment-oriented BCC model is as follows:

$$
\begin{array}{ll}
\operatorname{Min} & \mathrm{PTE}_{k} \\
\text { Subject to: } & \sum_{j=1}^{n} \lambda_{j} x_{i j}+s^{+}=\mathrm{PTE}_{k} x_{i k} \quad i=1,2, \ldots, m \\
& \sum_{j=1}^{n} \lambda_{j} y_{r j}-s^{-}=y_{r k} \quad r=1,2, \ldots, s \\
& \sum_{j=1}^{n} \lambda_{j}=1 \\
& \lambda_{j} \geq 0, \quad j=1,2, \ldots, n,
\end{array}
$$

where $x_{i j}$ stands for the input of creative human capital at $i$ in $j$ province and $y_{r j}$ stands for the output at $r$ in $j$ province, $\lambda_{j}$ is the weight in $j$ province, $s^{+}$stands for the input of creative human capital, and $s^{-}$stands for the slack variable of output of creative human capital, $0 \leq \mathrm{PTE} \leq 1$; the bigger the number, the purer the technical efficiency of creative human capital.

We can use CCR model to get technical efficiency (TE) of creative human capital, and according to relation from $\mathrm{TE}=$ $\mathrm{PTE} \times \mathrm{SE}$, we can get scale efficiency $(\mathrm{SE})$ :

$$
\begin{array}{ll}
\text { Min } & \mathrm{TE}_{k} \\
\text { Subject to: } & \sum_{j=1}^{n} \lambda_{j} x_{i j} \leq \mathrm{TE}_{k} x_{i k} \quad i=1,2, \ldots, m \\
& \sum_{j=1}^{n} \lambda_{j} y_{r j} \geq y_{r k} \quad r=1,2, \ldots, s \\
& \lambda_{j} \geq 0, \quad j=1,2, \ldots, n .
\end{array}
$$

2.2. The Second Stage: Establishing the SFA Model. When the output $y_{r j}$ does not change, if the management levels of creative human capital in all provinces are at the same level, the input of creative human capital $x_{i j}$ in good condition is less than the one in bad condition, which is affected by other provincial environment. Therefore, it cannot reflect the real level of management input of creative human capital. In order to get the real management efficiency of creative human capital in all provinces, it needs to strip the impact of environment variable and random errors and the internal management. According to the model which was put forward by Battese and Coelli in 1995, it can find regression model Stochastic Frontier Analysis (SFA) between $s_{i k}^{+}$and $z_{i k}$ as follows:

$$
\begin{aligned}
& s_{i k}^{+}=z_{i k} \beta+\left(v_{i k}+u_{i k}\right) \quad i=1,2, \ldots, m, \\
& k=1,2, \ldots, n \text {, }
\end{aligned}
$$

where $z_{i k}, \beta$ stand for the environment variable and index at $k$ in $i$ province, if $\beta<0$, so the environment variable is 
benefit for the decrease of slack variable and improves the technical efficiency, and vice versa. $v_{i k}+u_{i k}$ is composite error term, $v_{i k}$ is random variable, and it stands for the error which cannot take into consideration, $v_{i k}$ is single and $v_{i k} \sim N\left(0, \sigma_{v}^{2}\right), u_{i k}$ stands for management inefficiency factor, $u_{i k}$ is normal distribution, that is, $u_{i k}$ stands for $\sim N\left(\mu^{i}, \sigma_{u}^{2}\right)$, and $v_{i k}$ and $u_{i k}$ are independent of each other. Considering $\gamma=\sigma_{u}^{2} /\left(\sigma_{v}^{2}+\sigma_{u}^{2}\right), 0 \leq \gamma \leq 1, \gamma$ tend to be 1 , so that the impact of management variable is dominant; $\gamma$ tend to be 0 , so that the impact of random error is dominant.

We can get efficiency value which reflects the management level when considering the environment factor and random error using SFA model, adjust the input term of creative human capital, increase the input of provinces in good condition, and make the environment factor and random error in the same level; then we can get the input of the creative human capital $x_{i k}^{A}$ which, after adjusting, is

$$
\begin{array}{r}
x_{i k}^{A}=x_{i k}+\left[\max _{k}\left\{z_{i k} \widehat{\beta}^{i}\right\}-z_{i k} \widehat{\beta}^{i}\right]+\left[\max _{k}\left\{\widehat{v}_{i k}\right\}-\widehat{v}_{i k}\right] \\
i=1,2, \ldots, m, \quad k=1,2, \ldots, n,
\end{array}
$$

where $x_{i k}$ and $x_{i k}^{A}$ are creative human capital which are before and after adjusting, $\widehat{\beta}^{i}$ is the estimate of environment factor, $\widehat{v}_{i k}$ is the estimate of random error, the first bracket stands for adjusting the creative human capital in all provinces to the same environment, and the second bracket stands for adjusting the random errors of creative human capital to be the same.

2.3. The Third Stage: The DEA Model after Adjusting. Replace the original value $x_{i k}^{A}$ into the adjusted value, and use the BCC model to analyze the efficiency, so that we can get the efficiency value of creative human capital without the impact of environment factor and random errors.

\section{Variable Selection and Data Acquisition}

3.1. Output Variable. It is essential to select the reasonable input and output indicators for the final measurability of efficiency DMU when using DEA method to analyze the efficiency. A lot of researches have showed that education is the key part of human capital accumulation, and the state of education can measure the stock of human capital [10, 38]. Therefore, considering the characteristics of creative human capital, this research selected college students who receive college education or above as the research object and used the university graduates $\left(y_{1}\right)$ and the university students $\left(y_{2}\right)$ as output indicators.

3.2. Input Variable. Selection of input variables is reasonable to determine whether the analysis method is effective or not. In the selection of creative human capital input, the first difficulty is how to determine the origins of the input and the measurability of these variables [29]. Similar to the general process of input and output, the main factors which affect the creative human capital are the resources and factors in the production course, such as labor and capital. Combined with the measurability, the text selects college teachers $\left(x_{1}\right)$, college education spending $\left(x_{2}\right)$, college research spending $\left(x_{3}\right)$, and fixed assets $\left(x_{4}\right)$ as the input variables of creative human capital. The number of teaching staff in colleges or the education capital and fixed assets in institutions can directly affect the output level and the production scale of the creative human capital. And scientific research funds influence the output quality and efficiency of creative human capital.

\subsection{Environment Variable}

3.3.1. Scale Environment Variable. The enlargement of the education scale could directly increase the number of inputs of college education, improve the efficiency of education resources for the economic features of education scale, make full use of education resources, and ultimately improve the output of education. This paper selects the ordinary university number as the measure variable of scale environment.

3.3.2. Healthy Environment Variable. The good condition of health can not only improve the learning efficiency and the rate of return on education, but also affect the investment behavior on education. The better the health is, the longer the life is and the greater the benefit will be from the education [1]. And high human capital investment can resist the threat of disease or drug and optimize the quality of fertility [39]. As for the larger returns of creative human capital with high expected rate, good condition of health will get greater return from the higher education investment. Therefore, the development of healthy environment is bound to affect the investment behavior of people for higher education and to change the input and output of the creative human capital. The main measure variables of health indications are anthropometric variables, life expectancy or survival rate, mortality rate, and so forth [40]. This paper selects the population mortality $\left(z_{2}\right)$ as indicator of health environment variable.

3.3.3. Economic Environment Variable. On one hand, economic growth and the improvement of people's income will continue to encourage people to pursue higher quality of life, so as to increase the investment of education. On the other hand, with the constant improvement of the level of economic development, quality requirements of the talent will be much higher, and the talent competition will be much fiercer. In order to improve the competitive ability, more human capital investment is needed and creative human capital investment is on focus. So the economy will continue to promote the input and output growth of creative human capital. This paper selects GDP $\left(z_{3}\right)$ as measure variable of economic environment variable.

3.3.4. Skills Environment Variable. Training can be viewed as an extension of the education by making workers learn special skills during working, and it plays an important role in improving the level of workers' skills and working efficiency. Skill training is supposed to enhance the technical innovative ability and labor productivity of the trainees, improve their working and researching efficiency, and increase the input efficiency of human capital $[41,42]$. This paper selects the 
number of the students $\left(z_{4}\right)$ who graduate from technical college as measure indicator of skills environment variable.

3.3.5. Migration Environment Variable. Although population migration does not bring the increase of human capital stock, it can achieve the efficient allocation of human resources, so that the subjects of human capital can respond to the economic environment or system structure change effectively, find potential profit opportunities, and improve the decisionmaking ability to maximize the interests of using resources [27]. Migration can also increase the chances of migration employment and improve the utilization efficiency of social labor and employment [43]. This paper selects net migration rate as the migration environment variable.

3.3.6. Foreign Trade Environment Variable. Foreign trade not only can increase the total world trade, but also can accelerate the worldwide spread of advanced science, technology, and knowledge and make the participant countries benefit from the communication and trade [44]. Under different trade system, the effect of human capital on economic growth is not the same, and the effect is greater in open trade system than in the closed system [45]. This paper selects the total output $\left(z_{6}\right)$ as measure indicator of foreign trade environment variable.

3.3.7. Institution Environment Variable. Changes of institutions will not add the amount of human capital, but it may fully arouse the enthusiasm of human capital investor and human capital owner by establishing good institutional environment which includes the market-oriented economic system and human capital property right arrangements [46]. Therefore, the improvement of the institutional environment is conducive to optimizing the investment environment of creative human capital and improving the utilization efficiency of elements. This paper selects the proportion of the investment of non-state-owned economy fixed assets in the investment of the fixed assets of the whole society as the measuring indicator of institution environment variable.

3.4. Sample Statements. According to the purposes and needs of research, this paper selects 31 provincial districts in mainland of China as sample investigation objects; the time is from 2003 to 2010 (this research is using data during 2003-2010, as before 2003 the data about college was not distinguished in regions); the sample data come from "Statistical Yearbook," "the Statistical Yearbook of Education in China," "the Statistical Yearbook of Education Expenditure in China," "the Statistical Yearbook of Labor in China," and "the Population Statistics of Counties and Cities in China."

According to the request of research, there must be a significant correlation between various variables; inputs and outputs should comply with the "synthetic" hypothesis that production should increase with the increase of inventory. Variable with correlation test results such as Table 1 is obtained using Pearson's correlation test.

Table 1 shows that there is a significant correlation between output variable and input variable, and they are positively related, illustrating that the selection of variables and data is in accord with the requirement of model analysis and it is rational.

\section{The Empirical Analysis Results}

Then, through Deap2.1 and Front4.1 analyzing software, we made an empirical analysis of creative human capital technical efficiency of 31 provincial districts in China from 2003 to 2010 by using three-stage DEA method and made a horizontal comparison on the efficiency of various provincial districts; the specific analysis results are as follows.

Firstly, the overall efficiency of creative human capital is higher.

Table 2 shows the overall level of efficiency of creative human capital and its changes before and after considering the exogenous environment variables and random factors in China in sample period. In the process of the analysis of phase 1, the comprehensive technical efficiency average of creative human capital is 0.823 , average value of pure technical efficiency is 1 , the scale efficiency value is 0.823 , and the comprehensive technical efficiency value and scale efficiency value are on the decline, which indicates that the comprehensive technical efficiency of creative human capital has room for improvement and the scale efficiency is the main reason for technical inefficiency. In the analysis of phase 3, the influence of the environment variable and random errors on creative human capital is eliminated. Results show that the efficiency of three values is 1 , indicating that the technical efficiency in frontier has no room for improvement. Compared with the results of the first stage, the third stage of technical efficiency values rises to some extent, stating that the lower technical efficiency is mainly due to adverse circumstances or bad luck, rather than the technical management level.

Secondly, efficiency levels among eastern, western, and central regions roughly have the same change trend, but certain differences among these three regions still exist.

Through the analysis of the efficiency level among eastern, western, and central regions during phase 1 and phase 2 , the results in Table 3 show that, from 2003 to 2010, the average value of comprehensive technical efficiency and average of pure technical efficiency are both the highest in the eastern region, the next is in central region, and the lowest is in western region, while the highest scale efficiency value is in central region and next is in western region. And from 2003 to 2010, the average values of three regions all tend to decrease, which indicates that there is some room for improvement, and the efficiency value of pure technical efficiency is higher than the average value of scale efficiency; technical inefficiency is mainly due to scale inefficiency. Compared with the first stage, in the third phase, general average technical efficiency in these three areas and scale efficiency have obviously risen, and the pure efficiency values in eastern and western areas are slightly down, indicating that the technical efficiency value in three regions is closely related to their environment or bad luck, leading to some differences between the nominal technical management level and the actual technical management level.

We can find that the level of efficiency in central region is slightly higher than in the eastern and western regions 
TABLE 1: The correlation coefficient of variable test table.

\begin{tabular}{|c|c|c|c|c|c|}
\hline & & & & & \\
\hline & & $x_{1}$ & $x_{2}$ & $x_{3}$ & $x_{4}$ \\
\hline Outnut Variable & $y_{1}$ & $0.993^{* * *}$ & $0.974^{* * *}$ & $0.922^{* * *}$ & $0.993^{* * *}$ \\
\hline Uatput valiaute & $y_{2}$ & $0.998^{* * *}$ & $0.959^{* * *}$ & $0.912^{* * *}$ & $0.991^{* * *}$ \\
\hline & $z_{1}$ & $0.946^{* * *}$ & $0.969^{* * *}$ & $0.941^{* * *}$ & $0.965^{* * *}$ \\
\hline & $z_{2}$ & $0.952^{* * *}$ & $0.996^{* * *}$ & $0.984^{* * *}$ & $0.990^{* * *}$ \\
\hline & $z_{3}$ & $0.995^{* * *}$ & $0.960^{* * *}$ & $0.905^{* * *}$ & $0.988^{* * *}$ \\
\hline Environment variable & $z_{4}$ & $0.972^{* * *}$ & $0.944^{* * *}$ & $0.875^{* * *}$ & $0.966^{* * *}$ \\
\hline & $z_{5}$ & -0.537 & $-0.758^{* *}$ & $-0.812^{* *}$ & $-0.666^{*}$ \\
\hline & $z_{6}$ & $0.961^{* * *}$ & $0.958^{* * *}$ & $0.924^{* * *}$ & $0.967^{* * *}$ \\
\hline & $z_{7}$ & $0.884^{* * *}$ & $0.721^{* *}$ & $0.617^{*}$ & $0.799^{* *}$ \\
\hline
\end{tabular}

Note: ${ }^{*},{ }^{* *}$ and ${ }^{* * *}$ indicate significance at the $10 \%, 5 \%$ and $1 \%$ levels, respectively.

TABLE 2: Nationwide efficiency values of creative human capital during 2003-2010 in China.

\begin{tabular}{lcccccccccc}
\hline \multirow{5}{*}{ First stage } & & 2003 & 2004 & 2005 & 2006 & 2007 & 2008 & 2009 & 2010 & Mean \\
& TE & 0.844 & 0.851 & 0.825 & 0.825 & 0.800 & 0.806 & 0.816 & 0.815 & 0.823 \\
& PTE & 1.000 & 1.000 & 1.000 & 1.000 & 1.000 & 1.000 & 1.000 & 1.000 & 1.000 \\
\multirow{3}{*}{ Third stage } & SE & 0.844 & 0.851 & 0.825 & 0.825 & 0.800 & 0.806 & 0.816 & 0.815 & 0.823 \\
& TE & 1.000 & 1.000 & 1.000 & 1.000 & 1.000 & 1.000 & 1.000 & 1.000 & 1.000 \\
& PTE & 1.000 & 1.000 & 1.000 & 1.000 & 1.000 & 1.000 & 1.000 & 1.000 & 1.000 \\
& SE & 1.000 & 1.000 & 1.000 & 1.000 & 1.000 & 1.000 & 1.000 & 1.000 & 1.000 \\
\hline
\end{tabular}

through the comprehensive comparative analysis, partly because of the fact that the education investment proportion, which means the proportion between the nongovernmental education investment and governmental education investment, in the eastern and western education in recent years is relatively low. The improvement of education input from nongovernment will have a positive impact on accumulative level of human capital, so that the level of human capital in the region with higher education investment proportion will be relatively high [47].

Thirdly, nationwide and regional efficiency values of creative human capital keep declining.

From 2003 to 2010, the change of the creative human capital in the eastern, central, and western regions in China is shown in Figure 1. As we can see, level of the comprehensive technical efficiency in three regions from 2003 to 2007 continued to decline and started to rise in 2008, but there is an obvious overall decline from 2003 to 2010. In recent years the education input in China is increasing, but the education funds investment is relatively insufficient, the use efficiency of fund and the work efficiency of administrative personnel are low, and the differences of the regional development level among these regions are still evident. The higher education spending in China accounts merely for $1.25 \%$ in GDP from 2003 to 2010 and the college education investment is insufficient, which lead to the misallocation of higher education resource, low utilization efficiency of resources, and ultimate decline of the efficiency level of creative human capital. Therefore, increasing the investment of higher education funds, expanding the scale of college education, improving the efficiency level of education resources, and realizing the balanced development of regional education in colleges

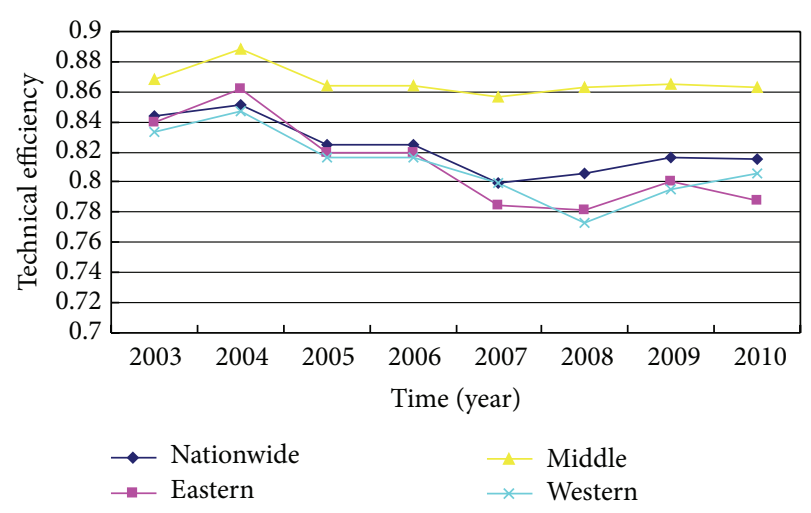

FIGURE 1: Description of changes of nationwide and regional efficiency values of creative human capital in China.

and universities are important measures and approaches to improve the technical efficiency level of creative human capital.

Fourthly, there is an obvious difference of creative human capital among various provinces and cities, significantly influenced by environment variables and random errors.

The average efficiency values of creative human capital in 31 provinces in China are shown in Table 4, by using panel data during 2003-2010. In the first phase analysis, in addition to Hebei, Shanxi, Henan, Guangxi, and Guizhou provinces that are in the frontier of technical efficiency level, the rest of provinces have a certain degree of technical inefficiency, indicating the room for improvement. The pure efficiency value in most provinces and cities is lower than the scale efficiency value, illustrating that technical nonefficiency is 
TABLE 3: Efficiency values of creative human capital in East, Middle, West parts during 2003-2010.

\begin{tabular}{|c|c|c|c|c|c|c|c|c|c|c|c|}
\hline & & & 2003 & 2004 & 2005 & 2006 & 2007 & 2008 & 2009 & 2010 & Mean \\
\hline \multirow{6}{*}{ East } & \multirow{3}{*}{ First stage } & $\mathrm{TE}$ & 0.840 & 0.862 & 0.820 & 0.820 & 0.785 & 0.782 & 0.801 & 0.788 & 0.812 \\
\hline & & PTE & 1.000 & 1.000 & 0.997 & 0.997 & 0.958 & 0.954 & 0.950 & 0.939 & 0.974 \\
\hline & & SE & 0.840 & 0.862 & 0.822 & 0.822 & 0.820 & 0.819 & 0.843 & 0.840 & 0.834 \\
\hline & \multirow{3}{*}{ Third stage } & $\mathrm{TE}$ & 0.999 & 1.000 & 0.992 & 0.953 & 0.959 & 0.950 & 0.921 & 0.913 & 0.961 \\
\hline & & PTE & 1.000 & 1.000 & 0.997 & 0.958 & 0.963 & 0.953 & 0.950 & 0.938 & 0.970 \\
\hline & & SE & 0.999 & 1.000 & 0.995 & 0.995 & 0.997 & 0.996 & 0.970 & 0.973 & 0.991 \\
\hline \multirow{6}{*}{ Middle } & \multirow{3}{*}{ First stage } & $\mathrm{TE}$ & 0.868 & 0.888 & 0.864 & 0.864 & 0.857 & 0.863 & 0.865 & 0.863 & 0.867 \\
\hline & & PTE & 1.000 & 1.000 & 1.000 & 1.000 & 1.000 & 1.000 & 1.000 & 1.000 & 1.000 \\
\hline & & SE & 0.868 & 0.888 & 0.864 & 0.864 & 0.857 & 0.863 & 0.865 & 0.863 & 0.867 \\
\hline & \multirow{3}{*}{ Third stage } & $\mathrm{TE}$ & 1.000 & 1.000 & 1.000 & 1.000 & 1.000 & 1.000 & 1.000 & 1.000 & 1.000 \\
\hline & & PTE & 1.000 & 1.000 & 1.000 & 1.000 & 1.000 & 1.000 & 1.000 & 1.000 & 1.000 \\
\hline & & SE & 1.000 & 1.000 & 1.000 & 1.000 & 1.000 & 1.000 & 1.000 & 1.000 & 1.000 \\
\hline \multirow{6}{*}{ West } & \multirow{3}{*}{ First stage } & $\mathrm{TE}$ & 0.833 & 0.847 & 0.816 & 0.816 & 0.799 & 0.773 & 0.795 & 0.806 & 0.811 \\
\hline & & PTE & 0.981 & 0.960 & 0.944 & 0.944 & 0.943 & 0.928 & 0.917 & 0.924 & 0.943 \\
\hline & & SE & 0.849 & 0.883 & 0.864 & 0.864 & 0.847 & 0.833 & 0.867 & 0.872 & 0.860 \\
\hline & \multirow{3}{*}{ Third stage } & $\mathrm{TE}$ & 0.943 & 0.932 & 0.931 & 0.901 & 0.909 & 0.916 & 0.916 & 0.915 & 0.920 \\
\hline & & PTE & 0.947 & 0.945 & 0.949 & 0.939 & 0.936 & 0.940 & 0.917 & 0.925 & 0.937 \\
\hline & & SE & 0.997 & 0.987 & 0.982 & 0.959 & 0.972 & 0.974 & 0.998 & 0.990 & 0.982 \\
\hline
\end{tabular}

Note: Eastern regions include Liaoning, Hebei, Beijing, Tianjin, Shandong, Jiangsu, Zhejiang, Shanghai, Fujian, Guangdong, Guangxi and Hainan; Middlel regions include Heilongjiang, Jilin, Inner Mongolia, Shanxi, Henan, Hubei, Jiangxi, Anhui and Hunan; western regions include Shaanxi, Gansu, Qinghai, Ningxia, Xinjiang, Sichuan, Chongqing, Yunnan, Guizhou and Tibet.

mainly due to pure technical nonefficiency, and the impact of scale inefficiency is relatively mild. Comparing the analysis results of the first stage and the third stage, the efficiency values of creative human capital among various provinces have greatly changed, after eliminating the influences of environment variables and random factors.

Table 4 shows that, in the stage 1, the efficiency level among those provinces and cities in the technical efficiency frontier declined in different extent, and the comprehensive technical efficiency values of all the 31 provinces and cities still have some room for improvement. Except Beijing, Liaoning, Jiangsu, Shandong, Hubei, and Guangzhou provinces, the comprehensive technical efficiency values of the rest of provinces and cities are declining, which illustrates that these provinces and cities are affected by the favorable environment or good luck and so that the comprehensive technical values are overvalued and these values in Qinghai, Guizhou, and Tibet provinces decreased obviously by $20 \%$. Otherwise, the scale efficiency is obviously declining compared with pure technical efficiency, indicating that the creative human capital is affected by the local environmental factors or luck, and the practical scale efficiency is lower, asking for enlarging the investment scale of creative human capital on the basis of existing condition. Besides, the pure technical efficiency values of most of the provinces and cities in third stage are increasing, indicating that the technical efficiency values are undervalued because of the environment variable or random errors, but the scale efficiency among these districts is always overvalued and the extent of overestimate is greater than the extent of underestimate, which may lead to the overestimate of comprehensive technical efficiency. After eliminating the influence of environment variable and random errors, three kinds of technical efficiency of creative human capital are all improved in some provinces like Beijing, Liaoning, Jiangsu, Shandong, Hubei, and Guangdong provinces, illustrating that the lower efficiency in these provinces and cities is due to the poor environment or bad luck, rather than their technical management level. Therefore, for these areas, it is particularly important to improve the investment environment of creative human capital.

Fifthly, environment variable can significantly affect input variables, but the direction is different.

Through the comparison of the efficiency values DEA in the first stage and the third stage, we can get that there is a significant impact of environment variable and random errors on creative human capital efficiency. The SFA model to analyze these results is shown in Table 5.

From the results of Table 5, the analysis results of SFA model are more reliable and the error is mainly due to the management inefficiency. There are seven environment variables affecting significantly the input slack variable, which means that the chosen environment variables are reasonable. We can get the result from the influence of environment variable on technical efficiency.

(1) The number of common colleges and universities obviously influences the reduction of the education expenditure, research expenditure, and fixed assets investment and the improvement of technical efficiency, which means that the expansion of education scale is conductive to forming scale economy of college education, optimizing the rational allocation of resources and improving the utilization efficiency of resources. However, its impact on the number 
TABLE 4: Average efficiency values of creative human capital in different provinces during 2003-2010.

\begin{tabular}{|c|c|c|c|c|c|c|}
\hline & \multicolumn{3}{|c|}{ First stage } & \multicolumn{3}{|c|}{ Third stage } \\
\hline & $\mathrm{TE}$ & PTE & SE & $\mathrm{TE}$ & PTE & $\mathrm{SE}$ \\
\hline Beijing & 0.512 & 0.513 & 0.997 & 0.524 & 0.645 & 0.815 \\
\hline Tianjin & 0.798 & 0.808 & 0.987 & 0.792 & 0.932 & 0.851 \\
\hline Hebei & 1.000 & 1.000 & 1.000 & 0.966 & 0.998 & 0.968 \\
\hline Shanxi & 1.000 & 1.000 & 1.000 & 0.804 & 0.990 & 0.812 \\
\hline Inner Mongolia & 0.885 & 0.897 & 0.986 & 0.738 & 0.958 & 0.771 \\
\hline Liaoning & 0.772 & 0.775 & 0.997 & 0.783 & 0.911 & 0.860 \\
\hline Jilin & 0.732 & 0.738 & 0.991 & 0.723 & 0.937 & 0.773 \\
\hline Heilongjiang & 0.753 & 0.761 & 0.990 & 0.755 & 0.887 & 0.852 \\
\hline Shanghai & 0.670 & 0.674 & 0.993 & 0.668 & 0.829 & 0.808 \\
\hline jiangsu & 0.891 & 0.941 & 0.947 & 0.943 & 0.952 & 0.990 \\
\hline Zhejiang & 0.910 & 0.913 & 0.997 & 0.907 & 0.940 & 0.966 \\
\hline Anhui & 0.993 & 0.994 & 0.998 & 0.988 & 0.997 & 0.991 \\
\hline Fujian & 0.869 & 0.875 & 0.993 & 0.860 & 0.961 & 0.896 \\
\hline Jiangxi & 0.988 & 0.990 & 0.999 & 0.954 & 0.990 & 0.964 \\
\hline Shandong & 0.960 & 0.991 & 0.968 & 0.993 & 1.000 & 0.993 \\
\hline Henan & 1.000 & 1.000 & 1.000 & 0.998 & 0.999 & 1.000 \\
\hline Hubei & 0.862 & 0.889 & 0.970 & 0.895 & 0.913 & 0.980 \\
\hline Hunan & 0.871 & 0.893 & 0.976 & 0.867 & 0.933 & 0.930 \\
\hline Guangdong & 0.891 & 0.899 & 0.991 & 0.953 & 1.000 & 0.953 \\
\hline Guangxi & 1.000 & 1.000 & 1.000 & 0.866 & 1.000 & 0.866 \\
\hline Hainan & 0.918 & 0.963 & 0.954 & 0.832 & 1.000 & 0.832 \\
\hline Chongqing & 0.851 & 0.859 & 0.990 & 0.840 & 0.913 & 0.920 \\
\hline Sichuan & 0.882 & 0.887 & 0.995 & 0.879 & 0.920 & 0.956 \\
\hline Guizhou & 1.000 & 1.000 & 1.000 & 0.774 & 0.966 & 0.803 \\
\hline Yunnan & 0.818 & 0.827 & 0.989 & 0.788 & 0.928 & 0.851 \\
\hline Tibet & 0.866 & 1.000 & 0.866 & 0.650 & 1.000 & 0.650 \\
\hline Shaanxi & 0.784 & 0.788 & 0.995 & 0.786 & 0.853 & 0.921 \\
\hline Gansu & 0.881 & 0.902 & 0.977 & 0.849 & 0.931 & 0.912 \\
\hline Qinghai & 0.920 & 1.000 & 0.920 & 0.486 & 0.982 & 0.495 \\
\hline Ningxia & 0.718 & 0.924 & 0.782 & 0.605 & 1.000 & 0.605 \\
\hline Xinjiang & 0.892 & 0.922 & 0.967 & 0.696 & 0.971 & 0.718 \\
\hline
\end{tabular}

TABLE 5: Regression analysis results of SFA.

\begin{tabular}{|c|c|c|c|c|}
\hline & $\begin{array}{c}\text { College teachers } \\
\text { slack variable }\end{array}$ & $\begin{array}{c}\text { College education } \\
\text { spending } \\
\text { slack variable }\end{array}$ & $\begin{array}{c}\text { College research } \\
\text { spending } \\
\text { slack variable }\end{array}$ & $\begin{array}{l}\text { Fixed assets } \\
\text { slack variable }\end{array}$ \\
\hline Constant & $-175.215^{* * *}$ & $-12863.3^{* * *}$ & $-27681.2^{* * *}$ & $-608690.7^{* * *}$ \\
\hline$z_{1}$ & 0.5843 & $-1704.90^{* * *}$ & $-117.45^{* *}$ & $-2126.92^{* * *}$ \\
\hline$z_{2}$ & -0.004916 & -3.0235 & $1.0414^{* *}$ & 2.7415 \\
\hline$z_{3}$ & $-0.000190^{* * *}$ & $-2.1062^{*}$ & $-0.5743^{* * *}$ & $-3.5655^{* *}$ \\
\hline$z_{4}$ & $-27.616^{* *}$ & $-80226.75^{* * *}$ & $-3244.31^{* *}$ & $-34122.78^{* * *}$ \\
\hline$z_{5}$ & $51.314^{* *}$ & $-7171.76^{* * *}$ & $-1864.96^{*}$ & $-34743.21^{* * *}$ \\
\hline$z_{6}$ & -0.008836 & $332.21^{* * *}$ & $24.8534^{* * *}$ & $364.11^{* * *}$ \\
\hline$z_{7}$ & -116.891 & $647439.9^{* * *}$ & $56196.33^{* * *}$ & $106449.7^{* * *}$ \\
\hline$\sigma^{2}$ & $0.259 E+07^{* * *}$ & $0.499 E+12^{* * *}$ & $0.540 E+10^{* * *}$ & $0.729 E+12^{* * *}$ \\
\hline$\gamma$ & $0.6831^{* * *}$ & $0.7359^{* * *}$ & $0.7406^{* * *}$ & $0.6420^{* * *}$ \\
\hline LR & $117.79^{* * *}$ & $131.02^{* * *}$ & $136.44^{* * *}$ & $85.54^{* * *}$ \\
\hline
\end{tabular}

Note: ${ }^{*},{ }^{* *}$ and ${ }^{* * *}$ indicate significance at the $10 \%, 5 \%$ and $1 \%$ levels, respectively. 
of faculty is not significant, probably because the increase of college teachers depends on the education level of teachers and the number of students. The competition among higher education universities is getting more and more intense, so each university and each region tend to adopt different policies and institutions to attract outstanding teachers, which may enhance the imbalance of resources allocation among different regions and universities and affect the efficiency of resource allocation.

(2) The regression coefficient of the effect of population mortality on the input of scientific research in colleges and universities is positive and it passed the significance test that shows that good and healthy environment (i.e., low mortality) is benefit for decrease of research input and improvement of technical efficiency, but its influence on the number of faculty, education funds, and fixed assets is not obvious. The main reason may be that good health condition can improve people's cognitive ability and maintain much longer mental working; then it would improve the efficiency of study and research and guarantee the quality of higher education returns and education input. Therefore, the influence of healthy environment is mainly to optimize the quality of colleges and the impact on the education scale factor is relatively small.

(3) The regression coefficients of the effect of GDP on input variables were negative and passed the test of significance, claiming that the increase of GDP is beneficial to the decrease of input for creative human capital and to improve the technical efficiency. The increase of GDP will lead to the improvement of the income of people and help to promote the residents' consumption quality and consumption level. Besides, it could raise the investment demand on the creative human capital, which is advantageous to realize the scale economy effect of local creative human capital and to improve the utilization efficiency and outputs efficiency of inputs.

(4) The regression coefficients of the effect of the number of the students who graduate from technical college on four input variables were negative and passed the test of significance, showing that the development of skills training is beneficial to the decrease of the creative human capital investment. The development of skills training can help the trainers get higher knowledge and skills and improve their innovation ability and the efficiency of work, research, and development, which not only can create better investment environment for creative human capital, but also can optimize the resource allocation efficiency and speed up the growth of input and output efficiency.

(5) Four kinds of inputs have passed the test of significance, indicating that the population migration will affect the inputs of creative human capital. And the regression coefficient of the effect of net migration rate on expenses of education in colleges and universities, scientific research spending and fixed assets, is negative, indicating that the increase of the rate of net migration is conducive to the reduction of the three elements of the input. Besides, the regression coefficient of the effect of net migration rate on the number of teaching staff members is positive, which means the number of teaching staff members will rise with the addition of the net migration rate. From the view of Dierx in 1988 [48], the main reason for attracting domestic population migration is the income growth, and when getting higher income through migration, people would increase the investment of human capital in order to ensure their living conditions. Therefore, the increase of population migration will expand the scale of creative human capital investment, be beneficial to form scale effect, and improve investment efficiency of elements. However, on the other hand, the effect of population migration also will be affected by the rationality of the cost of migration and migration among regions. Excessive or passive population migration is likely to cause the loss of the talent and the flight of human capital and reduce the labor productivity [43]. The current migration is happening mainly from rural villages to cities and from western regions to eastern regions. This unidirectional migration is mainly due to the imbalance of regional economic development. The imbalance of population migration is bound to lead to imbalance of resource allocation, which will waste the labor resources and decrease the utilization efficiency of labor resources. The irrationality of population migration will affect the input and allocation of faculty resources, and cause some problems, like the overstaffing of teachers, the antinomy between the utilitarian concept and moral concept, and the brain drain phenomenon. And then it would reduce the labor production efficiency.

(6) The influence of total import and export on the number of staff did not pass the test of significance, but the influence of education expenses in colleges and universities, scientific research spending and fixed assets, has passed the test of significance and the regression coefficient is positive, indicating that the development of foreign trade is not conductive to the decrease of three inputs. The possible reason would be that trade liberalization is beneficial to the introduction of technology, which will increase the human capital in countries with rich technology resources and decrease the human capital in countries with poor technology resources, by increasing the reward of technical elements and decreasing the reward of labor elements in countries with rich technology resources and increasing the reward of labor elements and decreasing the reward of technical elements in countries with poor technology resources [49]. China is a typical developing country, and excessive development of foreign trade in China will 
lead to more reliance on foreign technology, which is not conducive to the formation of scale effect of the creative human capital and the improvement of technical efficiency.

(7) The influence of the proportion of the investment of non-state economy fixed assets in the investment of the fixed assets of the whole society on the number of faculty did not pass the test of significance, but the influence on expenses of education in colleges and universities, the scientific research spending and fixed assets, has passed the test and the regression coefficient is positive, which means that the institutional change is bad for the improvement of technical efficiency and asks for more creative human capital investment. This is partly because the non-stateowned enterprises in China at present have not yet formed the scale economy, their technological content is low, and their consciousness of the innovative is not strong. Consequently, the economic system and education system have failed to be effectively combined, and the enthusiasm of creative human capital investors and owners is not fully aroused, wasting the human capital. So it is not conducive to the formation of scale economy creative human capital and the improvement of technical efficiency.

\section{Conclusion}

Based on the cognition of the continuous development of creative human capital and its increasing effect on economic growth, for the first time, this paper measures the technical efficiency value of the creative human capital in various cities from the perspective of technical efficiency and analyzes the main causes of inefficiency of human capital through the decomposition. By building the three-stage DEA model, this paper overcomes the defect of the traditional DEA and SFA method and makes the measurement of technical efficiency of creative human capital more accurate, by eliminating the influences of the exogenous environment variables and random errors and analyzing the reasons for the technical efficiency change from both the production technology level and the production scale.

Through the empirical research, we can get three conclusions. First, through the measurement and comparison of the technical efficiency level of creative human capital among different districts, the current level of comprehensive technical efficiency among different districts in China is relatively high but has not reached the optimal level and still has room to improve. According to the decomposition results of comprehensive technical efficiency, the main cause of inefficiency of creative human capital among different districts is that the production scale has not achieved the optimal production scale. In addition, through the comparison of technical efficiency between stage one and stage three, the environment factor and random error can also lead to technology inefficiency of creative human capital. From the point of time span, while the comprehensive technical efficiency level among different districts in China rose slightly after 2008, the technical efficiency level of creative human capital among different districts in China keeps declining in the long term.

Secondly, according to the measurement and comparison of the technical efficiency level of creative human capital among different provinces and cities, the comprehensive technical efficiency level of all provinces and cities has not reached the optimal level and needs to be improved. The reason of technical inefficiency of creative human capital among different provinces and cities still mainly lies in the inefficiency of the production scale and environment variables and random errors, while inefficiency of production technology has the slightest effect. The comparison results of the first stage and the third stage show that the theoretical technical efficiency level is overvalued compared with the practical technical efficiency level among most provinces and cities, except Beijing, Liaoning, Jiangsu, Shandong, Hubei, and Guangdong provinces. This is partly because the pure technical efficiency is usually underestimated and the scale efficiency is usually overvalued to some higher extent, which eventually leads to overvaluation of the comprehensive technical efficiency of creative human capital among these provinces and cities.

Thirdly, the analysis of environment variables shows that promotion of the technical efficiency of creative human capital is mostly significantly affected by the economic growth, the development of skill training, and the enlargement of the scale of universities, while the optimization of health environment and the acceleration of population migration also make a partial contribution to the improvement of the technical efficiency. However, the growth of international trade and the institutional change is not conducive to the development of the technical efficiency of creative human capital.

The research results indicate that China needs to constantly promote economic growth and increase education investment in higher education. At the same time, China needs to increase the creative human capital stock and try to achieve the optimal production scale of creative human capital. The economic growth can enable people to increase their investment in health and education especially higher education with more income and push the government to increase investment in higher education and realize the scale economy of higher education.

In recent years, although the higher education spending is increasing in China, there is still a certain gap compared with higher income countries. At present, the national higher education spending in China accounts for only $1.4 \%$ of total GDP, far below the 3\% level in high-income countries. In 2008, research and development expenditure as of GDP in China is $1.07 \%$ while the average level in the world is $2.14 \%$ and $2.14 \%$ in high-income countries. Despite the increasing scale of higher education since 1999 and its positive influence on the realization of the optimal scale of creative human capital, a series of problems such as inadequate education funds, the decrease of the higher education quality, and low efficiency of school management still exist and cause the low efficiency of the production scale and management of creative human capital. Therefore, it is important for China in the 
future to continuously increase higher education investment, optimize the education scale and education quality, and promote the utilization efficiency of education resources, in order to achieve the optimal level of technical efficiency of creative human capital and eventually develop the role of creative human capital in economic growth.

Otherwise, as the results show, the development of skill training and moderate population migration can also improve the technology efficiency of creative human capital. Effective skill training can be the supplement of higher education. Learning more professional skills inside or outside of their profession can improve students' technical level and work efficiency in the future. In addition, a moderate amount of vocational education during their practice and work can enable their innovation ability and promote their creative human capital stock. Besides, the labor resources will be rationally allocated and the utilization efficiency of production factors will be improved, because of the rational movement of creative human capital driven by population immigration. Therefore, in the future, developing vocational education should be emphasized as with expanding the higher education scale, to improve students' skill level. Meanwhile, the adjustment of industrial structure and the optimization of college profession allocation can help to realize the rational utilization of creative human capital.

In addition, adjusting the structure of foreign trade and preferring the economic property are also conducive to promote the technical efficiency of creative human capital. Currently in China, economic development relies too much on foreign trade and high foreign trade dependence will cause excessive dependence on foreign technology and innovation, which has negative effect on the formation of the scale effect of creative human capital. Consequently, adjusting the structure of foreign trade, expanding domestic demand, and increasing the proportion of domestic trade will help to promote economic growth, adjust the industrial structure, strengthen the domestic industry's capacity for independent innovation, and promote the utilization efficiency of creative human capital. And creating a good institutional environment with economic property rights system will also help, which would inspire the investors and owners of creative human capital to improve their technical efficiency.

In short, the development of China in the future needs to constantly adjust both economic and trade structure, and institutions, in order to improve the technology efficiency of creative human capital, make full use of creative human capital, and finally promote the economic growth.

\section{Conflict of Interests}

The authors declare that there is no conflict of interests regarding the publication of this paper.

\section{Acknowledgments}

This work was supported by the National Natural Science Foundation of China (NSFC) under Grant no. 71272067. It was also supported in part by the Ministry of education of Humanities and Social Science Fund Project under Grant no. 12YAJ630090, the Philosophy and Social Science Fund Project of Hunan Province under Grant no. 12YBB153, Soft Science Project of Hunan Province no. 2011ZK3077, and Scientific Research Project of the Education Department of Hunan Province no. 12C0787.

\section{References}

[1] J. Yang, L. Gong, and Q. Zhang, "Human capital formation land its effects on economic growth," Management World, no. 5, pp. 10-18, 2006.

[2] P. F. Zhu and D. F. Xu, "The estimation of human capital in Chinese cities," Economic Research Journal, no. 9, pp. 84-95, 2007.

[3] A. Ozyigit and F. Eminer, "Bounds test approach to the relationship between human capital and foreign direct investment as regressors of economic growth in Turkey," Applied Economics Letters, vol. 18, no. 6, pp. 561-565, 2011.

[4] D. J. Balan and S. Knack, "The correlation between human capital and morality and its effect on economic performance: theory and evidence," Journal of Comparative Economics, vol. 40, no. 3, pp. 457-475, 2012.

[5] P. Plummer and M. Taylor, "Entrepreneurship and human capital: distilling models of local economic growth to inform policy," Journal of Small Business and Enterprise Development, vol. 11, no. 4, pp. 427-439, 2004.

[6] P. Y. Hong and S. Pandey, "Human capital as structural vulnerability of US poverty," Equal Opportunities International, vol. 26, no. 1 , pp. 18-43, 2007.

[7] M. F. Khorasgani, "Higher education development and economic growth in Iran," Education, Business and Society, vol. 1, no. 3, pp. 162-174, 2008.

[8] Y. Jiang, X. Shi, S. Zhang, and J. Ji, “The threshold effect of highlevel human capital investment on China's urban-rural income gap," China Agricultural Economic Review, vol. 3, no. 3, pp. 297320, 2011

[9] T. W. Schultz, "The value of the ability to deal with disequilibria," Journal of Economic Literature, vol. 13, no. 3, pp. 827-846, 1975.

[10] N. G. Mankiw, D. Romer, and D. N. Weil, "A contribution to the empirics of economic growth," Quarterly Journal of Economics, vol. 107, no. 2, pp. 407-437, 1992.

[11] R. J. Barro and J. W. Lee, "International measures of schooling years and schooling quality," The American Economic Review, vol. 86, no. 2, pp. 218-223, 1996.

[12] R. Somanathan, "School heterogeneity, human capital accumulation, and standards," Journal of Public Economics, vol. 67, no. 3, pp. 369-397, 1998.

[13] T. Ayalew, "Parental preference, heterogeneity, and human capital inequality," Economic Development and Cultural Change, vol. 53, no. 2, pp. 381-407, 2005.

[14] A. Garcia-Aracil, J. G. Mora, and L. E. Vila, "The rewards of human capital competences for young European higher education graduates," Tertiary Education and Management, vol. 10, no. 4, pp. 287-305, 2004.

[15] R. Ramcharan, "Higher or basic education? The composition of human capital and economic development," IMF Staff Papers, vol. 51, no. 2, pp. 309-326, 2004.

[16] M. Fincher, "Governments as human capital providers: a rationale for strong government support of broad higher education access," Competitiveness Review, vol. 17, no. 1-2, pp. 67-76, 2007.

[17] A. van der Merwe, "Does human capital theory explain the value of higher education? A South African case study," The 
American Journal of Business Education, vol. 3, no. 1, pp. 107$118,2010$.

[18] T. Nakajima and H. Nakamura, "How do elementary and higher education affect human capital accumulation and inequality? A note," Macroeconomic Dynamics, vol. 16, no. 1, pp. 151-158, 2012.

[19] P. Romer, "Endogenous technological change," Journal of Political, vol. 98, no. 5, pp. 71-102, 1990.

[20] R. R. Nelson and E. S. Phelps, "Investment in humans, technological diffusion, and economic growth," The American Economic Review, vol. 56, no. 1-2, pp. 69-75, 1966.

[21] J. A. Schumpeter, The Theory of Economic Development, Oxford University Press, London, UK, 1934.

[22] R. E. Lucas Jr., "On the mechanics of economic development," Journal of Monetary Economics, vol. 22, no. 1, pp. 3-42, 1988.

[23] R. Florida, C. Mellander, and K. Stolarick, "Inside the black box of regional development-human capital, the creative class and tolerance," Journal of Economic Geography, vol. 8, no. 5, pp. 615649, 2008.

[24] C. Zhang and L. Zhuang, “The composition of human capital and economic growth: evidence from China using dynamic panel data analysis," China Economic Review, vol. 22, no. 1, pp. 165-171, 2011.

[25] H. W. Wang and P. Li, "Empirical analysis of the sources of China's economic growth in 1978-2008," Journal of KnowledgeBased Innovation in China, vol. 3, no. 2, pp. 91-105, 2011.

[26] H. Chen, "A structural analysis of the human capital's contribution to economy growth," The Journal of Quantitative \&Technical Economics, no. 8, pp. 9-68, 2007.

[27] J. Q. Guo, "Structural analysis of human capital investment," China Economic Quarterly, no. 3, pp. 689-706, 2005.

[28] C. Zhang, "Empirical research on the relation between formation of human capital and economic institutional transition," Economic Research Journal, no. 12, pp. 9-71, 2007.

[29] G. Ferrari and T. Laureti, "Evaluating technical efficiency of human capital formation in the Italian university: evidence from Florence," Statistical Methods and Applications, vol. 14, no. 2, pp. 243-270, 2005.

[30] C.-C. Chang, S.-W. Hung, and S.-Y. Huang, "Evaluating the operational performance of knowledge-based industries: the perspective of intellectual capital," Quality and Quantity, vol. 47, no. 3, pp. 1367-1383, 2011.

[31] M. A. Ahmed and G. Krishnasamy, "Human capital investment to achieve knowledge based economy in ASEAN5:DEA applications," Journal of the Knowledge Economy, vol. 4, no. 4, pp. 331342, 2013.

[32] J. Maudos, J. M. Pastor, and L. Serrano, "Human capital in OECD countries: technical change, efficiency and productivity," International Review of Applied Economics, vol. 17, no. 4, pp. 419435, 2003.

[33] C. L. Zhu, H. Z. Yue, and P. Shi, “The empirical study on the impact of human capital and its compositionon technical efficiency in China: the evidence based on the 1985-2007 provincial panel data," Studies in Science of Science, vol. 28, no. 11, pp. 1668-1672, 2010.

[34] L. P. Ran and F. Y. Zhai, "Empirical analysis on contribution rate of human capital in Chinese construction industry based on DEA," Journal of Systems \& Management, vol. 19, no. 6, pp. 702-705, 2010.

[35] H. O. Fried, C. A. K. Lovell, S. S. Schmidt, and S. Yaisawarng, "Accounting for environmental effects and statistical noise in data envelopment analysis," Journal of Productivity Analysis, vol. 17, no. 1-2, pp. 157-174, 2002.
[36] A. Charnes, W. W. Cooper, and E. Rhodes, "Measuring the efficiency of decision making units," European Journal of Operational Research, vol. 2, no. 6, pp. 429-444, 1978.

[37] R. D. Banker, A. Charnes, and W. W. Cooper, "Some models for estimating technical and scale inefficiencies in data envelopment analysis," Management Science, vol. 30, no. 9, pp. 10781092, 1984.

[38] H. Li and H. Liang, "Health, education, and economic growth in East Asia," Journal of Chinese Economic and Foreign Trade Studies, vol. 3, no. 2, pp. 110-131, 2010.

[39] F. Y. Tatoglu, "The relationships between human capital investment and economic growth: a panel error correction model," Journal of Economic and Social Research, vol. 13, no. 1, pp. 7588, 2011.

[40] D. E. Bloom, D. Canning, and J. Sevilla, "The effect of health on economic growth: a production function approach," World Development, vol. 32, no. 1, pp. 1-13, 2004.

[41] I. D. del Valle and M. A. S. Castillo, "Human capital and sustainable competitive advantage: an analysis of the relationship between training and performance," International Entrepreneurship and Management Journal, vol. 5, no. 2, pp. 139-163, 2009.

[42] S. Scicchitano, "Complementarity between heterogeneous human capital and R\&D: can job-training avoid low development traps?" Empirica, vol. 37, no. 4, pp. 361-380, 2010.

[43] J. E. Taylor and P. L. Martin, "Human capital: migration and rural population change," in Agricultural Production, vol. 1 of Handbook of Agricultural Economics, pp. 457-511, Elsevier, London, UK, 2001.

[44] D. X. Kan and L. W. Luo, "Empirical study on influence of foreign trade over human capital: based on provincial data in China," Research on Economics and Management, no. 4, pp. 117122, 2010.

[45] D. M. Gould and R. J. Ruffin, "Human capital, trade, and economic growth," Review of World Economics, vol. 131, no. 3, pp. 425-445, 1995.

[46] J. Y. Wang, "Impact of institutional changes on the role of human capital and physic capital in the process of economic growth," Chinese Journal of Population Science, no. 4, pp. 11-17, 2004.

[47] L. Y. Yu, "The ratio of education investment and differences in regional economic growth," Economic Research Journal, no. 10, pp. 131-143, 2008.

[48] A. H. Dierx, "Estimation of a human capital model of migration," The Annals of Regional Science, vol. 22, no. 3, pp. 99-110, 1988.

[49] C. W. Lai, Essays on international trade and human capital [A Dissertation for the Degree of Doctor of Philosophy], University of Virginia, 2008. 


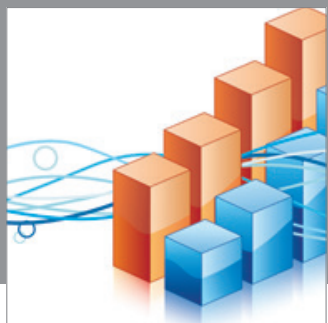

Advances in

Operations Research

mansans

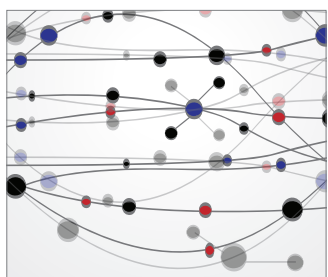

The Scientific World Journal
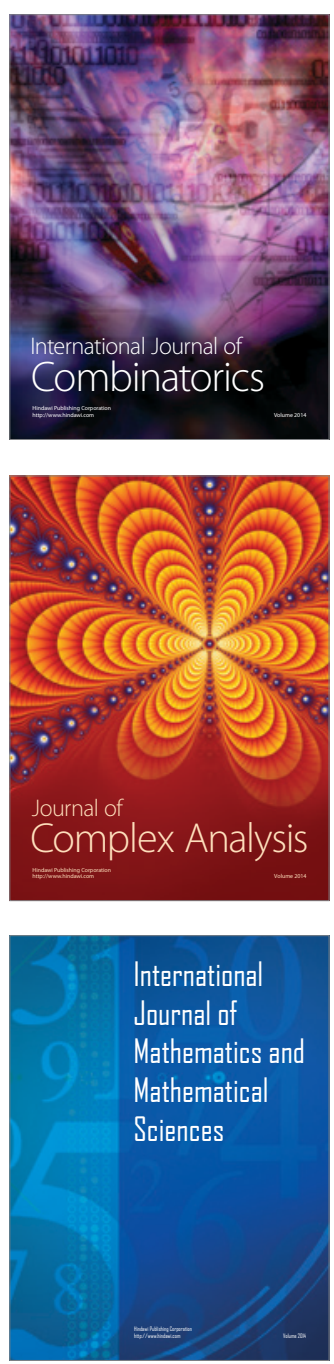
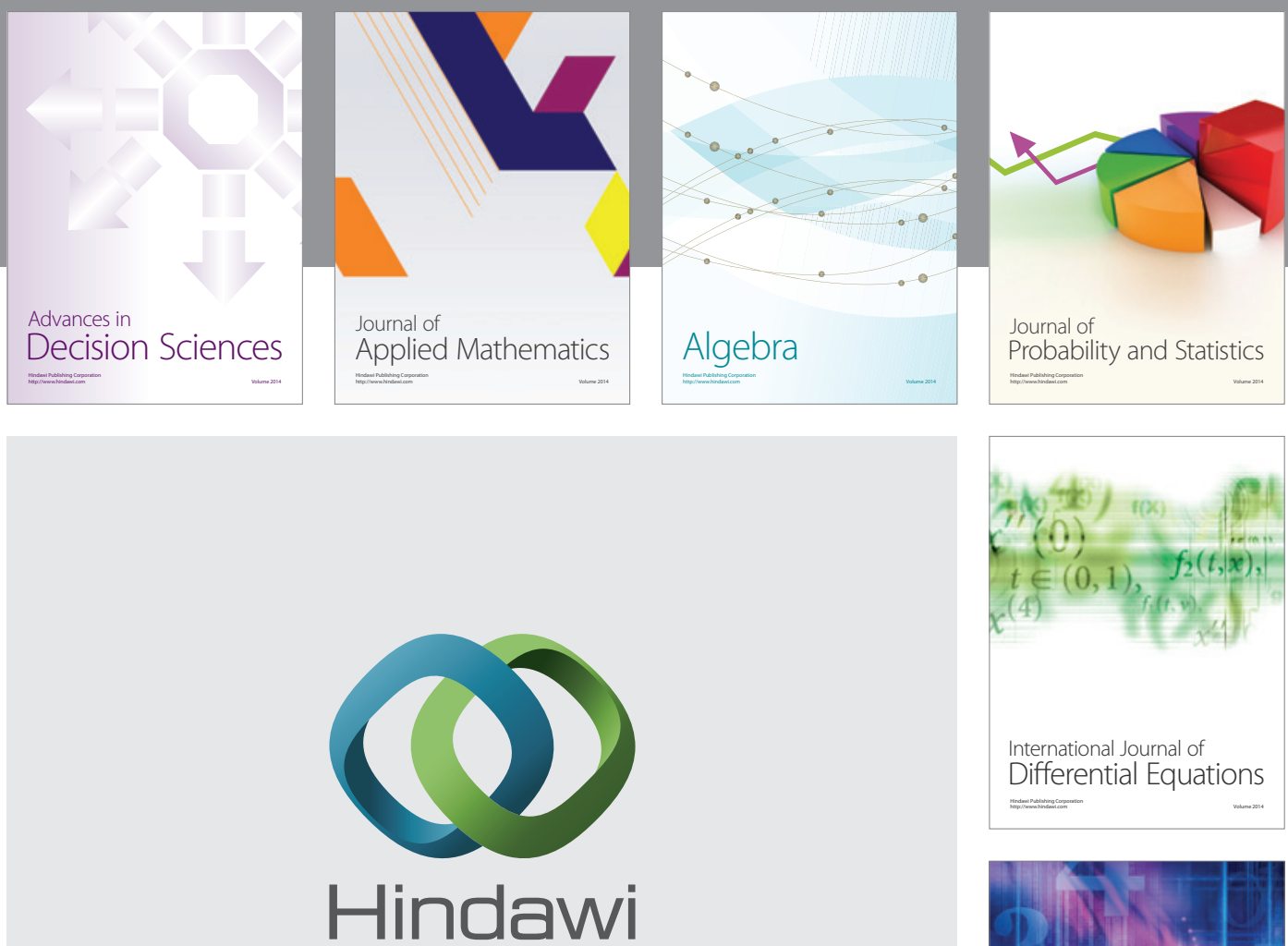

Submit your manuscripts at http://www.hindawi.com
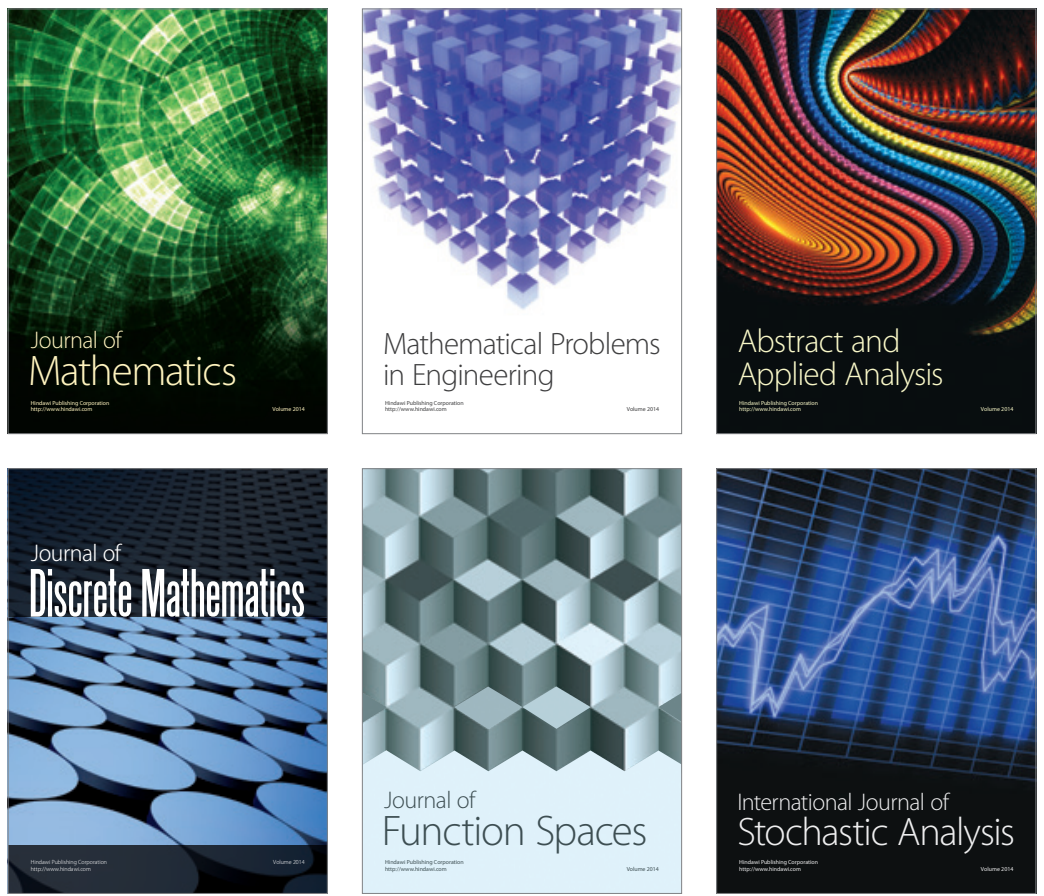

Journal of

Function Spaces

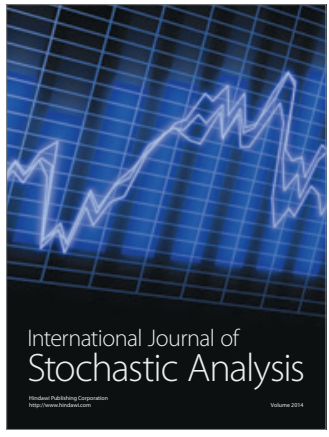

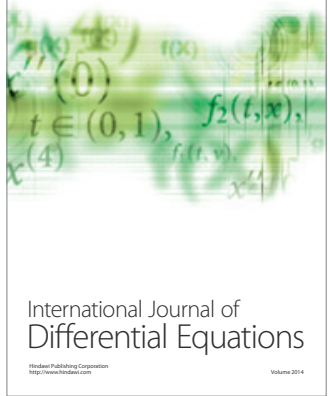
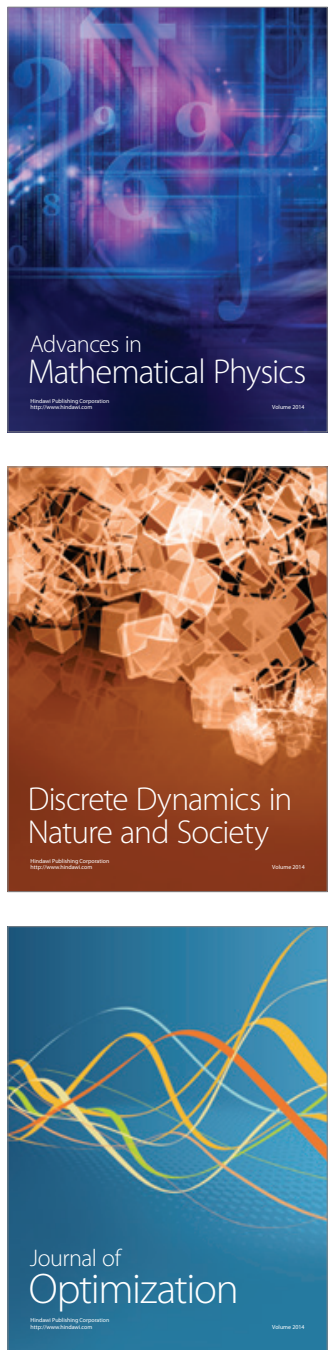